\title{
FURTHER PROPERTIES OF SOME MAPPINGS ASSOCIATED WITH HERMITE-HADAMARD INEQUALITIES
}

\author{
S. S. DRAGOMIR
}

Abstract. New properties of some functionals associated to the Hermite-Hadamard integral inequality for convex functions are given.

\section{Introduction}

Now for a given convex function $f:[a, b] \rightarrow \mathbb{R}$, let $H:[0,1] \rightarrow \mathbb{R}$ be defined by

$$
H(t):=\frac{1}{b-a} \int_{a}^{b} f\left(t x+(1-t) \frac{a+b}{2}\right) d x .
$$

The following theorem holds (see also [11], [13], [19] and [28]):

Theorem 1. With the above assumptions, we have:

(i) $H$ is convex on $[0,1]$;

(ii) One has the bounds:

$$
\inf _{t \in[0,1]} H(t)=H(0)=f\left(\frac{a+b}{2}\right)
$$

and

$$
\sup _{t \in[0,1]} H(t)=H(1)=\frac{1}{b-a} \int_{a}^{b} f(x) d x ;
$$

(iii) $H$ increases monotonically on $[0,1]$;

(iv) The following inequalities

$$
\begin{aligned}
f\left(\frac{a+b}{2}\right) & \leq \frac{2}{b-a} \int_{\frac{(3 a+b)}{4}}^{\frac{(a+3 b)}{4}} f(x) d x \\
& \leq \int_{0}^{1} H(t) d t \\
& \leq \frac{1}{2}\left(f\left(\frac{a+b}{2}\right)+\frac{1}{b-a} \int_{a}^{b} f(x) d x\right)
\end{aligned}
$$

Received December 28, 2001; revised March 5, 2002.

2000 Mathematics Subject Classification. Primary 26D15, secondary 26D10.

Key words and phrases. Hermite-Hadamard inequality. 
hold.

Now, we shall introduce another mapping which is connected with $H$ and the $H$. $-H$. result.

Let $f: I \subseteq \mathbb{R} \rightarrow \mathbb{R}$ be a convex function and $a, b \in I$ with $a<b$. Define the mapping $G:[0,1] \rightarrow \mathbb{R}$, given by

$$
G(t):=\frac{1}{2}\left[f\left(t a+(1-t) \frac{a+b}{2}\right)+f\left((1-t) \frac{a+b}{2}+t b\right)\right] .
$$

The following theorem contains some properties of this mapping [28]:

Theorem 2. Let $f$ and $G$ be as above. Then

(i) $G$ is convex and monotonically increasing on $[0,1]$;

(ii) We have the bounds:

$$
\inf _{t \in[0,1]} G(t)=G(0)=f\left(\frac{a+b}{2}\right)
$$

and

$$
\sup _{t \in[0,1]} G(t)=G(1)=\frac{f(a)+f(b)}{2} ;
$$

(iii) One has the inequality

$$
H(t) \leq G(t) \quad \text { for all } \quad t \in[0,1]
$$

(iv) One has the inequalities

$$
\begin{aligned}
\frac{2}{b-a} \int_{\frac{(3 a+b)}{4}}^{\frac{(a+3 b)}{4}} f(x) d x & \leq \frac{1}{2}\left[f\left(\frac{3 a+b}{4}\right)+f\left(\frac{a+3 b}{4}\right)\right] \\
& \leq \int_{0}^{1} G(t) d t \\
& \leq \frac{1}{2}\left[f\left(\frac{a+b}{2}\right)+\frac{f(a)+f(b)}{2}\right] .
\end{aligned}
$$

Now, we shall consider another mapping associated with the Hermite-Hadamard inequality given by $L:[0,1] \rightarrow \mathbb{R}$,

$$
L(t):=\frac{1}{2(b-a)} \int_{a}^{b}[f(t a+(1-t) x)+f((1-t) x+t b)] d x
$$

where $f: I \subseteq \mathbb{R} \rightarrow \mathbb{R}$ and $a, b \in I$ with $a<b$.

The following theorem also holds [28]:

Theorem 3. With the above assumptions one has: 
(i) $L$ is convex on $[0,1]$;

(ii) We have the inequalities:

$$
G(t) \leq L(t) \leq \frac{1-t}{b-a} \cdot \int_{a}^{b} f(x) d x+t \cdot \frac{f(a)+f(b)}{2} \leq \frac{f(a)+f(b)}{2}
$$

for all $t \in[0,1]$ and the bound:

$$
\sup _{t \in[0,1]} L(t)=\frac{f(a)+f(b)}{2}
$$

(iii) One has the inequalities:

$$
H(1-t) \leq L(t) \quad \text { and } \quad \frac{H(t)+H(1-t)}{2} \leq L(t)
$$

for all $t \in[0,1]$.

Now, we shall introduce another mapping defined by a double integral in connection with the Hermite-Hadamard inequalities:

$$
F:[0,1] \rightarrow \mathbb{R}, \quad F(t):=\frac{1}{(b-a)^{2}} \int_{a}^{b} \int_{a}^{b} f(t x+(1-t) y) d x d y
$$

The following theorem holds [19] (see also [13]):

Theorem 4. Let $f:[a, b] \rightarrow \mathbb{R}$ be as above. Then

(i) $F\left(\tau+\frac{1}{2}\right)=F\left(\frac{1}{2}-\tau\right)$ for all $\tau \in\left[0, \frac{1}{2}\right]$ and $F(t)=F(1-t)$ for all $t \in[0,1]$;

(ii) $F$ is convex on $[0,1]$;

(iii) We have the bounds:

$$
\sup _{t \in[0,1]} F(t)=F(0)=F(1)=\frac{1}{b-a} \int_{a}^{b} f(x) d x
$$

and

$$
\inf _{t \in[0,1]} F(t)=F\left(\frac{1}{2}\right)=F(1)=\frac{1}{(b-a)^{2}} \int_{a}^{b} \int_{a}^{b} f\left(\frac{x+y}{2}\right) d x d y ;
$$

(iv) The following inequality holds:

$$
f\left(\frac{a+b}{2}\right) \leq F\left(\frac{1}{2}\right)
$$

(v) F decreases monotonically on $\left[0, \frac{1}{2}\right]$ and increases monotonically on $\left[\frac{1}{2}, 1\right]$;

(vi) We have the inequality:

$$
H(t) \leq F(t) \text { for all } t \in[0,1]
$$


In what follows, we shall point out some reverse inequalities for the mappings $H, G$, $L$ and $F$ considered above.

We shall start with the following result [17] (see also [58]).

Theorem 5. Let $f: I \subseteq \mathbb{R} \rightarrow \mathbb{R}$ be a convex mapping on $I$ and $a, b \in \stackrel{\circ}{I}$ with $a<b$. Then we have the inequality:

$$
\begin{aligned}
0 & \leq \frac{1}{b-a} \int_{a}^{b} f(x) d x-H(t) \\
& \leq(1-t)\left[\frac{f(a)+f(b)}{2}-\frac{1}{b-a} \int_{a}^{b} f(x) d x\right]
\end{aligned}
$$

for all $t \in[0,1]$.

Corollary 1. With the above assumptions, one has

$$
\begin{aligned}
0 & \leq \frac{1}{b-a} \int_{a}^{b} f(x) d x-\frac{2}{b-a} \int_{\frac{(3 a+b)}{4}}^{\frac{(a+3 b)}{4}} f(x) d x \\
& \leq \frac{1}{2}\left[\frac{f(a)+f(b)}{2}-\frac{1}{b-a} \int_{a}^{b} f(x) d x\right] .
\end{aligned}
$$

Remark 1. If in (1.5) we choose $t=0$, we obtain

$$
0 \leq \frac{1}{b-a} \int_{a}^{b} f(x) d x-f\left(\frac{a+b}{2}\right) \leq \frac{f(a)+f(b)}{2}-\frac{1}{b-a} \int_{a}^{b} f(x) d x,
$$

which is the well-known Bullen result [62, p.140].

Another theorem of this type in which the mapping $G$ defined above is involved, is the following one:

Theorem 6. Let $f: I \subseteq \mathbb{R} \rightarrow \mathbb{R}$ be a convex mapping on $I$ and $a, b \in \stackrel{\circ}{I}$ with $a<b$. Then we have the inequality:

$$
0 \leq H(t)-f\left(\frac{a+b}{2}\right) \leq G(t)-H(t)
$$

for all $t \in[0,1]$.

Proof. It is sufficient to prove the above inequality for differentiable convex functions. By the convexity of $f$, we have that

$$
f\left(\frac{a+b}{2}\right)-f\left(t x+(1-t) \frac{a+b}{2}\right) \leq t\left(\frac{a+b}{2}-x\right) f^{\prime}\left(t x+(1-t) \frac{a+b}{2}\right)
$$


for all $x$ in $(a, b)$ and $t \in[0,1]$.

Integrating this inequality over $x$ on $[a, b]$ one gets

$$
f\left(\frac{a+b}{2}\right)-H(t) \geq \frac{t}{b-a} \int_{a}^{b}\left(\frac{a+b}{2}-x\right) f^{\prime}\left(t x+(1-t) \frac{a+b}{2}\right) d x .
$$

As a simple calculation (an integration by parts) yields that

$$
\frac{t}{b-a} \int_{a}^{b}\left(\frac{a+b}{2}-x\right) f^{\prime}\left(t x+(1-t) \frac{a+b}{2}\right) d x=H(t)-G(t), \quad t \in[0,1],
$$

then, the above inequality gives us the desired result (1.6).

Remark 2. If in the above inequality we choose $t=1$, we also recapture Bullen's result $[62, \mathrm{p} .140]$.

\section{Some New Results}

Now, we shall investigate the case of the mapping $F$ defined by the use of double integrals ([17] and [58])

Theorem 7. Let $f: I \subseteq \mathbb{R} \rightarrow \mathbb{R}$ be a convex mapping on $I$ and $a, b \in \stackrel{\circ}{I}$ with $a<b$. Then we have the inequality:

$$
\begin{aligned}
0 & \leq \frac{1}{b-a} \int_{a}^{b} f(x) d x-F(t) \\
& \leq \min \{t, 1-t\}\left(\frac{f(a)+f(b)}{2}-\frac{1}{b-a} \int_{a}^{b} f(x) d x\right)
\end{aligned}
$$

for all $t \in[0,1]$.

Proof. As above, it is sufficient to prove the above inequality for differentiable convex functions.

Thus, for all $x, y \in(a, b)$ and $f \in[0,1]$ we have:

$$
f(t x+(1-t) y)-f(y) \geq t(x-y) f^{\prime}(y) .
$$

Integrating this inequality on $[a, b]^{2}$ over $x$ and $y$, we obtain

$$
\int_{a}^{b} \int_{a}^{b} f(t x+(1-t) y) d x d y-(b-a) \int_{a}^{b} f(x) d x \geq t \int_{a}^{b} \int_{a}^{b}(x-y) f^{\prime}(y) d x d y
$$

for all $t \in[0,1]$.

As a simple computation shows that

$$
\int_{a}^{b} \int_{a}^{b}(x-y) f^{\prime}(y) d x d y=(b-a) \int_{a}^{b} f(x) d x-(b-a)^{2} \cdot \frac{f(a)+f(b)}{2},
$$


the above inequality gives us that

$$
\frac{1}{b-a} \int_{a}^{b} f(x) d x-F(t) \leq t\left[\frac{f(a)+f(b)}{2}-\frac{1}{b-a} \int_{a}^{b} f(x) d x\right]
$$

for all $t \in[0,1]$.

As $F(t)=F(1-t)$ for all $t \in[0,1]$, if we replace in the above inequality $t$ with $1-t$ we get the desired result (2.1).

Corollary 2. With the above assumptions, one has:

$$
\begin{aligned}
0 & \leq \frac{1}{b-a} \int_{a}^{b} f(x) d x-\frac{1}{(b-a)^{2}} \int_{a}^{b} \int_{a}^{b} f\left(\frac{x+y}{2}\right) d x d y \\
& \leq \frac{1}{2}\left[\frac{f(a)+f(b)}{2}-\frac{1}{b-a} \int_{a}^{b} f(x) d x\right] .
\end{aligned}
$$

Now, let us define the mapping $J:[0,1] \rightarrow \mathbb{R}, J(t):=L(1-t)$, i.e.,

$$
J(t)=\frac{1}{2(b-a)} \int_{a}^{b}[f(t x+(1-t) a)+f(t x+(1-t) b)] d x,
$$

where $t \in[0,1]$.

We have the following result:

Theorem 8. Let $f$ and $a, b \in \stackrel{\circ}{I}$ be as above. Then we have the inequality:

$$
0 \leq F(t)-H(t) \leq J(t)-F(t)
$$

for all $t \in[0,1]$.

Proof. As above, it is sufficient to prove the above inequality for differentiable convex functions.

By the convexity of $f$ on $[a, b]$ we have that

$$
f\left(t x+(1-t) \frac{a+b}{2}\right)-f(t x+(1-t) y) \geq(1-t) f^{\prime}(t x+(1-t) y)\left(\frac{a+b}{2}-y\right)
$$

for all $x, y \in(a, b)$ and $t \in[0,1]$.

If we integrate over $x$ and $y$ on $[a, b]^{2}$, we get that:

$$
\begin{aligned}
& \int_{a}^{b} \int_{a}^{b} f\left(t x+(1-t) \frac{a+b}{2}\right) d x d y-\int_{a}^{b} \int_{a}^{b} f(t x+(1-t) y) d x d y \\
\geq & (1-t) \int_{a}^{b} \int_{a}^{b} f^{\prime}(t x+(1-t) y)\left(\frac{a+b}{2}-y\right) d x d y
\end{aligned}
$$


which gives us that:

$$
\begin{aligned}
0 & \leq F(t)-H(t) \\
& \leq \frac{1-t}{(b-a)^{2}} \int_{a}^{b} \int_{a}^{b} f^{\prime}(t x+(1-t) y)\left(y-\frac{a+b}{2}\right) d x d y=: A(t)
\end{aligned}
$$

for all $t \in[0,1]$.

Define

$$
I_{1}(t):=\frac{1-t}{(b-a)^{2}} \int_{a}^{b} \int_{a}^{b} f^{\prime}(t x+(1-t) y) y d x d y
$$

and

$$
I_{2}(t):=\frac{1-t}{(b-a)^{2}} \int_{a}^{b} \int_{a}^{b} f^{\prime}(t x+(1-t) y) d x d y .
$$

Note that, for $t=1$, the inequality (2.2) is obvious. Assume that $t \in[0,1)$. Integrating by parts, we get that:

$\int_{a}^{b} f^{\prime}(t x+(1-t) y) y d y=\frac{f((1-t) b+t x) b-f((1-t) a+t x) a}{1-t}-\frac{1}{1-t} \int_{a}^{b} f((1-t) y+t x) d y$.

Thus, we deduce that

$$
I_{1}(t)=\frac{b \int_{a}^{b} f(t x+(1-t) b) d x-a \int_{a}^{b} f(t x+(1-t) a) d x}{(b-a)^{2}}-F(t) .
$$

We also have

$$
\int_{a}^{b} f^{\prime}(t x+(1-t) y) d y=\frac{f(t x+(1-t) b)-f(t x+(1-t) a)}{1-t}
$$

and thus

$$
I_{2}(t)=\frac{\int_{a}^{b} f(t x+(1-t) b) d x-\int_{a}^{b} f(t x+(1-t) a) d x}{(b-a)^{2}} .
$$

Now, we get that

$$
\begin{aligned}
A(t)= & \frac{b \int_{a}^{b} f(t x+(1-t) b) d x-a \int_{a}^{b} f(t x+(1-t) a) d x}{(b-a)^{2}}-F(t) \\
& -\frac{a+b}{2} \cdot \frac{\int_{a}^{b} f(t x+(1-t) b) d x-\int_{a}^{b} f(t x+(1-t) a) d x}{(b-a)^{2}} \\
= & \frac{\frac{b-a}{2} \int_{a}^{b} f(t x+(1-t) b) d x+\frac{b-a}{2} \int_{a}^{b} f(t x+(1-t) a) d x}{(b-a)^{2}}-F(t) \\
= & J(t)-F(t)
\end{aligned}
$$

and the theorem is proved. 
Corollary 3. With the above assumptions, we have:

$$
0 \leq F(t)-\frac{H(t)+H(1-t)}{2} \leq \frac{L(t)+L(1-t)}{2}-F(t)
$$

for all $t \in[0,1]$.

Finally, the following theorem holds.

Theorem 9. Let $f: I \subseteq \mathbb{R} \rightarrow \mathbb{R}$ be a convex function on $I$ and $a, b \in \stackrel{\circ}{I}$ with $a<b$. Then one has the inequality

$$
\begin{aligned}
0 & \leq F(t)-F\left(\frac{1}{2}\right) \\
& \leq \frac{1}{2 t(1-t)}\left[(1-2 t)^{2} F(t)-\frac{1-2 t}{b-a} \cdot \int_{(1-t) a+t b}^{t a+(1-t) b} f(x) d x\right]
\end{aligned}
$$

for all $t \in(0,1)$.

Proof. As above, we can prove the inequality (2.3) only for the case where $f$ is a differentiable convex function.

By the convexity of $f$ we have that:

$$
\begin{aligned}
& f\left(\frac{x+y}{2}\right)-f(t x+(1-t) y) \\
\geq & {\left[\frac{x+y}{2}-(t x+(1-t) y)\right] f^{\prime}(t x+(1-t) y) } \\
= & \frac{1-2 t}{2}(x-y) f^{\prime}(t x+(1-t) y)
\end{aligned}
$$

for all $x, y \in(a, b)$ and $t \in[0,1]$.

If we integrate the inequality (2.4) over $x, y$ on $[a, b]^{2}$ we can deduce

$$
F\left(\frac{1}{2}\right)-F(t) \geq \frac{1-2 t}{2} \cdot \frac{1}{(b-a)^{2}} \int_{a}^{b} \int_{a}^{b}(x-y) f^{\prime}(t x+(1-t) y) d x d y
$$

Denote

and

$$
\begin{aligned}
I(t) & :=\frac{1}{(b-a)^{2}} \int_{a}^{b} \int_{a}^{b}(x-y) f^{\prime}(t x+(1-t) y) d x d y \\
I_{1}(t) & :=\frac{1}{(b-a)^{2}} \int_{a}^{b} \int_{a}^{b} x f^{\prime}(t x+(1-t) y) d x d y
\end{aligned}
$$

$$
I_{2}(t):=\frac{1}{(b-a)^{2}} \int_{a}^{b} \int_{a}^{b} y f^{\prime}(t x+(1-t) y) d x d y
$$


Then we have $I(t)=I_{1}(t)-I_{2}(t)$ for all $t \in[0,1]$.

An integration by parts gives us that

$$
\int_{a}^{b} x f^{\prime}(t x+(1-t) y) d x=\left.\frac{x f(t x+(1-t) y)}{t}\right|_{a} ^{b}-\frac{1}{t} \int_{a}^{b} f(t x+(1-t) y) d x
$$

then

$$
\begin{aligned}
I_{1}(t) & =\frac{1}{(b-a)^{2}} \int_{a}^{b}\left[\frac{f(t b+(1-t) y) b-f(t a+(1-t) y) a}{t}-\frac{1}{t} \int_{a}^{b} f(t x+(1-t) y) d x\right] d y \\
& =\frac{1}{(b-a)^{2}} \cdot \frac{1}{t}\left[b \int_{a}^{b} f(t b+(1-t) y) d y-a \int_{a}^{b} f(t a+(1-t) y) d y\right]-\frac{1}{t} F(t) .
\end{aligned}
$$

Also, by an integration by parts, we have:

$$
\int_{a}^{b} y f^{\prime}(t x+(1-t) y) d x=\left.\frac{f(t x+(1-t) y) y}{1-t}\right|_{a} ^{b}-\frac{1}{1-t} \int_{a}^{b} f(t x+(1-t) y) d y
$$

then we obtain:

$$
\begin{aligned}
I_{2}(t) & =\frac{1}{(b-a)^{2}} \int_{a}^{b}\left[\frac{f(t x+(1-t) b) b-f(t x+(1-t) a) a}{1-t}-\frac{1}{1-t} \int_{a}^{b} f(t x+(1-t) y) d y\right] d x \\
& =\frac{1}{(b-a)^{2}} \cdot \frac{1}{1-t}\left[b \int_{a}^{b} f(t x+(1-t) b) d x-a \int_{a}^{b} f(t x+(1-t) a) d x\right]-\frac{1}{1-t} F(t) .
\end{aligned}
$$

Thus, we have

$$
\begin{aligned}
I(t)= & \frac{1}{t(b-a)^{2}} \cdot\left[b \int_{a}^{b} f(t b+(1-t) y) d y-a \int_{a}^{b} f(t a+(1-t) y) d y\right]-\frac{1}{t} F(t) \\
& -\frac{1}{(1-t)(b-a)^{2}} \cdot\left[b \int_{a}^{b} f(t x+(1-t) b) d x-a \int_{a}^{b} f(t x+(1-t) a) d x\right]+\frac{1}{1-t} F(t) \\
= & \frac{2 t-1}{t(1-t)} \cdot F(t)+\frac{1}{t(1-t)(b-a)^{2}} \cdot V(t),
\end{aligned}
$$

where

$$
\begin{aligned}
V(t)= & (1-t) b \int_{a}^{b} f(t b+(1-t) y) d y-(1-t) a \int_{a}^{b} f(t a+(1-t) y) d y \\
& -t b \int_{a}^{b} f(t x+(1-t) b) d x+t a \int_{a}^{b} f(t x+(1-t) a) d x \\
= & b \int_{(1-t) a+t b}^{b} f(u) d u-a \int_{a}^{(1-t) b+t a} f(u) d u-b \int_{t a+(1-t) b}^{b} f(u) d u+a \int_{a}^{t b+(1-t) a} f(u) d u
\end{aligned}
$$




$$
\begin{aligned}
& =b \int_{(1-t) a+t b}^{t a+(1-t) b} f(u) d u-a \int_{(1-t) a+t b}^{t a+(1-t) b} f(u) d u \\
& =(b-a) \int_{(1-t) a+t b}^{t a+(1-t) b} f(x) d x .
\end{aligned}
$$

Consequently, we have

$$
\begin{aligned}
F\left(\frac{1}{2}\right)-F(t) & \geq \frac{1-2 t}{2} \cdot I(t) \\
& =\frac{1-2 t}{2}\left[\frac{2 t-1}{t(1-t)} \cdot F(t)+\frac{1}{(b-a) t(1-t)} \int_{(1-t) a+t b}^{t a+(1-t) b} f(x) d x\right] \\
& =\frac{1-2 t}{2(b-a) t(1-t)} \int_{(1-t) a+t b}^{t a+(1-t) b} f(x) d x-\frac{(2 t-1)^{2}}{2 t(1-t)} F(t)
\end{aligned}
$$

for all $t \in(0,1)$, which is equivalent with the desired inequality (2.3).

\section{References}

[1] G. Allasia, C. Giordano, J. Pečarić, Hadamard-type inequalities for (2r)-convex functions with applications, Atti Acad. Sci. Torino-Cl. Sc. Fis. 133(1999), 1-14.

[2] H. Alzer, A note on Hadamard's inequalities, C. R. Math. Rep. Acad. Sci. Canada 11(1989), 255-258.

[3] H. Alzer, On an integral inequality, Math. Rev. Anal. Numer. Theor. Approx. 18(1989), 101-103.

[4] A. G. Azpeitia, Convex functions and the Hadamard inequality, Rev.-Colombiana-Mat. 28(1994), 7-12.

[5] D. Barbu, S. S. Dragomir and C. Buşe, A probabilistic argument for the convergence of some sequences associated to Hadamard's inequality, Studia Univ. Babeş-Bolyai, Math. 38(1)(1993), 29-33.

[6] E. F. Beckenbach, Convex functions, Bull. Amer. Math. Soc. 54(1948), 439-460.

[7] C. Borell, Integral inequalities for generalized concave and convex functions, J. Math. Anal. Appl. 43(1973), 419-440.

[8] C. Buşe, S. S. Dragomir and D. Barbu, The convergence of some sequences connected to Hadamard's inequality, Demostratio Math. 29(1996), 53-59.

[9] L. J. Dedić, C. E. M. Pearce and J. Pečarić, The Euler formulae and convex functions, Math. Ineq. and Appl. 2(2000), 211-221.

[10] L. J. Dedić, C. E. M. Pearce and J. Pečarić, Hadamard and Dragomir-Argarwai inequalities, high-order convexity and the Euler Formula, submitted.

[11] S. S. Dragomir, A mapping in connvection to Hadamard's inequalities, An. Öster. Akad. Wiss. Math.-Natur. 128(1991), 17-20. MR 934:26032. ZBL No.747:26015.

[12] S. S. Dragomir, A refinement of Hadamard's inequality for isotonic linear functionals, Tamkang J. of Math. 24(1993), 101-106. MR 94a: 26043. 2BL No.799:26016.

[13] S. S. Dragomir, On Hadamard's inequality for convex functions, Mat. Balkanica 6(1992), 215-222. MR: 934:26033. 
[14] S. S. Dragomir, On Hadamard's inequality for the convex mappings defined on a ball in the space and applications, Math. Ineq. and Appl. 3(2000), 177-187.

[15] S. S. Dragomir, On Hadamard's inequality on a disk, Journal of Ineq. in Pure and Appl. Maht. 1(2000), Article 2, http://jipam.vu.edu.au/ No.1

[16] S. S. Dragomir, On some integral inequalities for convex functions, Zb.-Rad. (Kragujevac) (1996), 21-25.

[17] S. S. Dragomir, Some integral inequalities for differentiable convex functions, Contributions, Macedonian Acad. of Sci. and Arts 13(1992), 13-17.

[18] S. S. Dragomir, Some remarks on Hadamard's inequalities for convex functions, Extracta Math. 9(1994), 88-94.

[19] S. S. Dragomir, Two mappings in connection to Hadamard's inequalities, J. Math. Anal. Appl. 167(1992), 49-56. MR:934:26038, ZBL No.758:26014.

[20] S. S. Dragomir and R. P. Agarwal, Two inequalities for differentiable mappings and applications to special means of real numbers and to trapezoidal formula, Appl. Mat. Lett. 11(1998), 91-95.

[21] S. S. Dragomir and R. P. Agarwal, Two new mappings associated with Hadamard's inequalities for convex functions, Appl. Math. Lett. 11(1998), 33-38.

[22] S. S. Dragomir and C. Buşe, Refinements of Hadamard's inequality for multiple integrals, Utilitas Math 47(1995), 193-195.

[23] S. S. Dragomir, Y. J. Cho and S. S. Kim, Inequalities of Hadamard's type for Lipschitzian mappings and their applications, J. of Math. Anal. Appl. 245(2000), 489-501.

[24] S. S. Dragomir and S. Fitzpatrick, The Hadamard's inequality for s-convex functions in the first sense, Demonstratio Math. 31(1998), 633-642.

[25] S. S. Dragomir and S. Fitzpatrick, The Hadamard's inequality for s-convex functions in the second sense, Demonstratio Math. 32(1999), 687-696.

[26] S. S. Dragomir and N. M. Ionescu, On some inequalities for convex-dominated functions, Anal. Num. Theor. Approx. 19(1990), 21-28. MR 936:26014 ZBL No.733:26010.

[27] S. S. Dragomir and N. M. Ionescu, Some integral inequalities for differentiable convex functions, Coll. Pap. of the Fac. of Sci. Kragujevac (Yugoslavia) 13(1992), 11-16, ZBL No.770.

[28] S. S. Dragomir, D. S. Milośević and J. Sándor, On some refinements of Hadamard's inequalities and applications, Univ. Belgrad, Publ. Elek. Fak. Sci. Math. 4(1993), 21-24.

[29] S. S. Dragomir and B. Mond, On Hadamard's inequality for a class of functions of Godunova and Levin, Indian J. Math. 39(1997), 1-9.

[30] S. S. Dragomir and C. E. M. Pearce, Quasi-convex functions and Hadamard's inequality, Bull. Austral. Math. Soc. 57(1998), 377-385.

[31] S. S. Dragomir, C. E. M. Pearce and J. E. Pečarić, On Jessen's and related inequalities for isotonic sublinear functionals, Acta Math. Sci. (Szeged) 61(1995), 373-382.

[32] S. S. Dragomir, J. E. Pečarić and L. E. Persson, Some inequalities of Hadamard type, Soochow J. of Math. 21(1995), 335-341.

[33] S. S. Dragomir, J. E. Pečarić and J. Sándor, A note on the Jensen-Hadamard inequality, Anal. Num. Theor. Approx. 19(1990), 21-28. MR 93b: 260 14. ZBL No.733:26010.

[34] S. S. Dragomir and G. H. Toader, Some inequalities for $m$-convex functions, Studia Univ. Babeş-Bolyai, Math. 38(1993), 21-28.

[35] A. M. Fink, A best possible Hadamard inequality, Math. Ineq. and Appl. 2(1998), 223-230.

[36] A. M. Fink, Hadamard inequalities for logarithmic concave functions, Boundary value problems and related topics, Math. Comput. Modeling, 32(2000), 625-629. 
[37] A. M. Fink, Toward a theory of best possible inequalities, Nieuw Archief von Wiskunde 12(1994), 19-29.

[38] A. M. Fink, Two inequalities, Univ. Beograd Publ. Elektrotehn. Fak. Ser. Mat. 6(1995), 48-49.

[39] B. Gavrea, On Hadamard's inequality for the convex mappings defined on a convex domain in the space, Journal of Ineq. in Pure and Appl. Math. 1(2000), Article 9, http://jipam.vu. edu.au/

[40] P. M. Gill, C. E. M. Pearce and J. Pečarić, Hadamard's inequality for $r$-convex functions, J. of Math. Anal. and Appl. 215(1997), 461-470.

[41] G. H. Hardy, J. E. Littlewood and G. Pólya, Inequalities, 2nd Ed., Cambridge University Press, 1952.

[42] K.-C. Lee and K.-L. Tseng, On a weighted generalisation of Hadamard's Inequality for G-convex functions, Tamsui Oxford Journal of Math. Sci. 16(2000), 91-104.

[43] A. Lupaş, The Jensen-Hadamard inequality for convex functions of higher order, Octogon Math. Mag. 5(1997), 8-9.

[44] A. Lupaş, A generalisation of Hadamard inequalities for convex functions, Online: (http:// rgmia.vu.edu.au/authors/ALupas.htm).

[45] A. Lupaş, Jensen-Hadamard inequality for convex functions of higher order, Online: (http:// rgmia.vu.edu.au/authors/ALupas.htm).

[46] A. Lupaş, A generalisation of Hadamard's inequality for convex functions, Univ. Beograd. Publ. Elek. Fak. Ser. Mat. Fiz. No.544-576(1976), 115-121.

[47] D. M. Makisimović, A short proof of generalized Hadamard's inequalities, Univ. Begrad. Publ. Elektrotehn. Fak. Ser. Mat. Fiz. No.634-677(1979), 126-128.

[48] D. S. Mitrinović and I. Lacković, Hermite and convexity, Aequat. Math. 28(1985), 229-232.

[49] D. S. Mitrinović, J. E. Pečarić and A. M. Fink, Classical and New Inequalities in Analysis, Kluwer Academic Publishers, Dordrecht/Boston/London.

[50] B. Mond and J. E. Pečarić, A companion to Fink's inequality, Octogon Math. Mag. 5(1997), 12-18.

[51] E. Neuman, Inequalities involving generalized symmetric means, J. Math. Anal. Appl. 120(1986), 315-320.

[52] E. Neuman and J. E. Pečarić, Inequalities involving multivariate convex functions, J. Math. Anal. Appl. 137(1989), 514-549.

[53] E. Neuman, Inequalities involving multivariate convex functions II, Proc. Amer. Math. Soc. 109(1990), 965-974.

[54] C. P. Niculescu, A Note on the Dual Hermite-Hadamard Inequality, The Math. Gazette, July, 2000.

[55] C. P. Niculescu, Convexity according to the geometric mean, Math. Ineq. and Appl. 3(2000), 155-167.

[56] C. E. M. Pearce, J. Pečarić and V. Šimić, Stolarsky means and Hadamard's inequality, J. Math. Anal. Appl. 220(1998), 99-109.

[57] C. E. M. Pearce and A. M. Rubinov, P-functions, quasi-convex functions and Hadamardtype inequalities, J. Math. Anal. Appl. 240(1999), 92-104.

[58] J. E. Pečarić, Remarks on two interpolations of Hadamard's inequalities, Contributions, Macedonian Acad. of Sci. and Arts, Sect. of Math. and Technical Sciences, (Scopje) 13(1992), 9-12.

[59] J. Pečarić and V. Čuljak, On Hadamard inequalities for logarithmic convex functions, submitted. 
[60] J. Pečarić, V. Čuljak and A. M. Fink, On some inequalities for convex functions of higher order, Nonlinear Stud. 6(1999), 131-140.

[61] J. Pečarić, V. and S. S. Dragomir, A generalization of Hadamard's integral inequality for isotonic linear functionals, Rudovi Mat. (Sarajevo) 7(1991), 103-107. MR 924:26026. 2BL No.738:26006.

[62] J. Pečarić, F. Proschan and Y. L. Tong, Convex Functions, Partial Orderings and Statistical Applications, Academic Press, Inc., 1992.

[63] F. Qi and Q.-M. Luo, Refinements and extensions of an inequality, Mathematics and Informatics Quarterly 9(1999), 23-25.

[64] F. Qi, S.-L. Xu, and L. Debnath, A new proof of monotonicity for extended mean values, Intern. J. Math. Sci. 22(1999), 415-420.

[65] A. W. Roberts and P. E. Varberg, Convex Functions, Academic Press, 1973.

[66] F. Saidi and R. Younis, Hadamard and Fejer-type Inequalities, Archiv der Mathematik. 74(2000), 30-39.

[67] J. Sándor, A note on the Jensen-Hadamard inequality, Anal. Numer. Theor. Approx 19(1990), 29-34.

[68] J. Sándor, An application of the Jensen-Hadamard inequality, Nieuw-Arch.-Wisk. 8(1990), 63-66.

[69] J. Sándor, On the Jensen-Hadamard inequality, Studia Univ. Babes-Bolyai, Math. 36(1991), $9-15$.

[70] G. H. Toader, Some generalisations of the convexity, Proc. Colloq. Approx. Optim, ClujNapoca (Romania), 1984, 329-338.

[71] P. M. Vasić, I. B. Lacković and D. M. Maksimović, Note on convex functions IV: OnHadamard's inequality for weighted arithmetic means, Univ. Beograd Publ. Elek. Fak., Ser. Mat. Fiz. No.678-715(1980), 199-205.

[72] G. S. Yang and M. C. Hong, A note on Hadamard's inequality, Tamkang J. Math., 28(1997), 33-37.

[73] G. S. Yang and K. L. Tseng, On certain integral inequalities related to Hermite-Hadamard inequalities, J. Math. Anal. Appl. 239(1999), 180-187.

School of Communications and Informatics, Victoria University of Technology, PO Box 14428, Melbourne City MC, 8001, Victoria, Australia.

E-mail: sever@matilda.vu.edu.au

URL: http://rgmia.vu.edu.au/SSDragomirWeb.html 